\title{
Developing Multiplication Fact Fluency
}

\author{
Jonathan Brendefur \\ Boise State University. United States \\ Strother, $\mathbf{S}$. \\ Boise State University. United States \\ Thiede, $\mathrm{K}$. \\ Boise State University. United States
}

Appleton, $\mathrm{S}$.

Meridian School District

\begin{abstract}
INTRODUCTION
Based on the poor performance of fourth grade students on national and international tests of mathematics, it is evident that students are not adequately prepared in mathematics (Duncan et al., 2007; Reese, Miller, Mazzeo, \& Dossey, 1997). Although there are multiple factors which may contribute to these deficiencies, one key factor is automaticity of students' multiplication facts (Kilpatrick, Swafford, \& Findell, 2001; National Mathematics Advisory Panel, 2008). The ability to become better problem solvers entails decreasing a student's cognitive load in order to increase the amount of energy spent on solving the problem versus trying to remember facts (Nelson, Burns, Kanive, \& Ysseldyke, 2013; Speiser, Schneps, Heffner-Wong, Miller, \& Sonnert, 2012). In addition, this flexibility leads to fluency and efficiency with various numbers and across contexts (Russell, 2000; Young-Loveridge \& Mills, 2009).
\end{abstract}

More locally, teachers of intermediate grades students frequently express frustration at students' lack of fluency with basic multiplication facts (Boonlerts \& Inprasitha, 2013; Campbell, Chen, \& Maslany, 2013; Mulligan \& Mitchelmore, 2009; Wong \& Evans, 2007). This lack of fluency affects other mathematical topics as diverse as multi-digit multiplication and division, ratio and proportion, measurement conversions, and fraction concepts as well as long term performance in mathematics classrooms (Kilpatrick et al., 2001; NMAP, 2008). What makes this study different than others, is the nature of practice students engaged in and the combination of cognitive and social processes used as a foundation for instruction. The purpose of this study is to focus on an intervention that builds on flexible strategy choice through multiple representations (Bruner, 1964) in order to increase students' fact fluency levels.

\section{Fluency and Flexibility}

Based on an analysis of the relevant research literature, we hypothesized that an increase in fluency would occur if flexibility and conceptual understanding were the desired goals and emphasis of instruction (Fuson, 2003; Star \& Madnani, 2004; Steffe, 1979; Van Amerom, 2003). For this study, we define fluency as the ability to recall basic facts accurately and quickly and is attained by a measure of a timed fact test at an approximate rate of 3 seconds or less per fact (Van Putten, van den Brom-Sniiders, \& Beishuizen, 2005). We define flexibility as the ability to solve problems in a variety of ways, use information already known to solve unknown 
problems, and the capability to determine the most efficient method to use when confronted with a challenging problem (Beishuizen \& Anghileri, 1998). Essentially, if students work on reasoning flexibly with basic multiplication facts, they will in turn become more fluent on measures of basic facts recall.

Given international and national concerns with multiplication fluency and the immediate and long-term impediments to performing well in mathematics, many studies have focused on supporting struggling students by providing them with drill or rehearsal techniques versus engaging them in more flexible or conceptual practice (NMAP, 2008). Numerous researchers have found that for struggling learners, many with learning disabilities, drill and rehearsal techniques can increase students' short term gains in multiplication fluency (Geary, 2004; Jordan, Hanich, \& Kaplan, 2003; Nelson et al., 2013). One major issue is that these gains in fluency do not always translate to flexible use of facts in problem solving or applications with later mathematics (Geary, Hoard, Byrd-Craven, Nugent, \& Numtee, 2007). In a meta-analysis, Coding et al (2011) noted that for students who are labeled with learning difficulties or are in the lowest quartile for mathematics, drill and practice with modeling had the greatest treatment effects on fluency. Another set of researchers have found that when all students engage in more flexible and conceptual approaches to learning facts, their fluency increases as does their ability to transfer these skills to move novel situations (Gray, Pitta, \& Tall, 2000; Mulligan \& Mitchelmore, 2009).

These different intervention approaches on learning can produce different instructional techniques for increasing fact fluency (Henry \& Brown, 2008; Thornton, 1978). Therefore, it becomes important to explicate and apply a framework to the topic of fact fluency to understand effective techniques for increasing fluency for all students, not just struggling learners.

Drawing from social-interactional approach, we view basic multiplication fact fluency instruction to require a general assumption that cognitive theories are also applicable as internal mental networks or schemas. For example, troublesome facts would, in theory, become easier to recall quickly when they are related to well-known facts the child retains with limited practice. Many children-including struggling learners-find multiplication by 2, 5 , and 10 to be easier to retain in memory than other multiplication facts (Baroody \& Dowker, 2003). Thus, learning to use a fact such as $8 \times 5$ as an "anchor" by which to connect $8 \times 6,8 \times 7$, or even $8 \times 4$ to the child's mental schema network would be the goal of cognition-based fact fluency development. However, to construct and grow the learner's schema, the learner must be placed in situations in which knowledge and ideas are shared with peers (for example two students may discuss their own individualized related facts they use to remember 8x7) and ideas must be communicated through symbols and representations that allow for all learners to examine the fact fluency strategies being shared. In order to build these internal schemas, imagery and iconic models to represent multiplication become necessary (Bruner, 1966; Gray et al., 2000; Speiser et al., 2012).

\section{Modes of Representation}

As students discuss their own personal strategies to remember troublesome facts (e.g. 8x7) a cognitive "wall" can inhibit students from understanding the strategies described by their peers (Cobb, Yackel, \& Wood, 1993 1993; Mulligan \& Mitchelmore, 2009). Many strategies for deriving unknown facts tend to be individualized and allow the student to use a single fact to remember a group of related facts. But, these known facts may differ between students and in an effort to increase both the number of facts easily recalled and the fluency by which the recall 
process occurs it becomes necessary for students to understand a broad selection of strategies to derive basic facts in a social-interactional or cognitive realm. Relying on memory alone is deemed too great an instructional risk as memory capacity is a limiting factor in building computational fluency (Geary, 2004; Geary, Liu, \& Siegler, 1996). But if a peer's facts strategies are not those a student is familiar with, how can they "learn" to use this new information?

Bruner's theory of Modes of Representation offers a gradual progression how ideas can be presented that can help students internalize and communicate new information. In Bruner's theory, he offers three modes that we can use to represent concepts as we attempt to learn the concepts; enactive, iconic, and symbolic (Bruner, 1966). First, the Enactive Mode is the form of representation in which ideas are presented as real tangible parts of the environment. Physical objects can be used to represent specific concepts as students try to model their thinking. Second, the Iconic representations, which are essentially drawings and diagrams that simulate the enactive representations, take them from being actual physical objects to approximations. The third mode in Bruner's theoretical progression is the Symbolic representations, which are the formal means by which we present abstract ideas. Notation and oral language are examples. Words, written or verbalized, have no meaning without a culturally agreed upon system that gives them meaning.

If Bruner's theory is applied to fact fluency, students would first engage in modeling facts and facts strategies using physical, enactive models such as counters and tiles. They would also be challenged with finding examples of groupings and arrays (rectangular arrangements of rows and columns) that model multiplication problems in their surrounding environment (e.g. arrays of windows, tiled floors, or rows of chairs) (Barmby, Harries, Higgins, \& Suggate, 2009). After examining enactive representations of multiplication, students would then draw iconic diagrams of arrays and groupings that would offer a subsequent opportunity to label the iconic representations with symbolic notation (e.g. mathematical symbols and words). Students would then engage in symbolic-focused practice by either discussing facts strategies with peers orally or practicing multiplication facts using only cards to cue their recall and symbolic notation to clarify their ideas.

\section{METHOD}

From the research, it is clear that struggling learners increased their fluency scores (Geary, 2004; Jordan et al., 2003; Nelson et al., 2013), but it is less clear that a strategy approach does (Fuson, 2003; Woodward, 2006). Thus, we wanted to find out whether focusing on a socialinteractional approach that uses cognitive impact features (in our case, enactive, iconic, and symbolic representations) would improve third, fourth, and fifth grade students' fact fluency compared to typical classroom approach of drill and rehearsal techniques. We chose a quasiexperimental design to answer the question.

\section{Setting}

The treatment and comparison teachers were chosen from a school district with six Title 1 schools located in a U.S. western city. The schools had a history of below average performance on the state standardized achievement test and the schools ranged from 63 to 89 percent of their students on free and reduced price lunch status and 11 to 30 percent English Language Learners. We randomly selected two of the schools to be part of the treatment and two of the schools to serve as the comparison. There were 5 teachers from the selected treatment schools who were willing to participate (one teaching grade 3 , three teaching grade 4 , and one teaching grade 5) and 7 teachers who agree to part of the comparison group (one teaching grade 3, three teaching grade 4 , and three teaching grade 5 ). 


\section{Participants and Design}

Participants were 282 students enrolled in third, fourth and fifth grade classrooms. In third grade, 25 students were assigned to the Strategy group and 25 to the Drill group. In fourth grade, 65 students were assigned to the Strategy group and 69 to the Drill group. In fifth grade, 24 students were assigned to the Strategy group and 74 to the Drill group. Group (Strategy versus Drill) and Grade (3 versus 4 versus 5) were between-subjects variables.

The multiplication fluency test consisted of 30 items (Appendix A) and was administered before and immediately after the five-week unit. Time (pretest versus posttest) was a withinsubjects variable. Thus, we had a 2 (Group: Strategy versus Drill) x 3 (Grade: 3, 4, 5) x 2 (Time: Pretest versus Posttest) design.

\section{Procedure}

All students completed a 30 item multiplication fluency pretest. Teachers then taught a fiveweek unit on multiplication fluency. As noted next, the Strategy group received instruction based on cognitive and social-interactional framework for fluency development; whereas, the Drill group received fluency instruction for basic multiplication facts using an approach emphasizing memorization and rehearsal techniques typically practiced in schools. Following the five-week unit, students again completed the 30 item multiplication fluency posttest.

\section{Intervention}

To examine the changes in students' multiplication fact fluency, a 5 week study was constructed. The study compared a treatment group to a comparison group of 3rd, 4th, and 5th grade students that received two different approaches to fluency development. Both groups received fluency instruction for a minimum of 10 minutes and a maximum of 15 minutes each day for the duration of the five weeks.

The treatment or Strategy group received instruction based on cognitive and socialinteractional theories for fluency development. That is, theories of cognition were used to guide the focus of instruction towards providing students experiences intended to build their relational thinking among multiplication facts and encourage students to enhance their mental schemas for basic facts. Social-interactional theories were primarily implemented using Bruner's Modes of Representation progression to guide instruction. Students first used enactive models to examine facts and facts strategies and then progressed to iconic and symbolic representations.

For the strategy classrooms, an instructional unit had to be designed as there were no readily available curricular materials that approached fact fluency from a predominantly cognitive or social-interactional perspective. The unit had four distinct sections that were sequenced as follows with each section lasting between 4-6 days:

1. Strategy group students began by building arrays with physical models (e.g. tiles) and finding arrays in pictures as well as the surrounding environment. Students then drew diagrams of the arrays on either grid paper (to structure the drawings) or freehand.

2. Students then transitioned from arrays to using a $12 \times 12$ blank grid as a multiplication table as both a way to list facts they knew but also as an example of an array. Students overlaid their derived facts strategies (e.g. $8 \times 5+8 \times 1$ to recall $8 \times 6$ ) on these $12 \times 12$ multiplication grids.

3. Eventually, students' materials were removed and they were engaged in what was called "fluency-talks". Students sat on the floor with no writing materials or 
manipulatives available and were presented with various facts. They had to discuss as a class how they might use related facts to solve the unknown facts presented on the board.

4. To culminate the strategy group's fact development, pairs of students created sets of strategy cards, which were essentially multiplication flash cards (with a fact on the front of the card), but strategy cards included derived facts strategies the pair preferred written on the back of the card. The pairs would alternate describing two or three facts strategies for each card's fact.

In the sequence and design of the strategy group's tasks one can observe a direct implementation of Bruner's representational modes. Initially, students use a blend of enactive and iconic models examine and express ideas. Gradually, they began using a blend of iconic and symbolic models and eventually only symbolic representations (e.g. notation and oral language). In contrast, the drill groups' activities included a timed math fact test each day followed by traditional flash card practice sessions as well as various songs and mnemonic exercises designed to commit facts to memory. The comparison group or what we label the Drill group received fluency instruction for basic multiplication facts using an approach emphasizing memorization, rehearsal, and rewards systems. Classroom tasks and activities for the drill classrooms were chosen based on readily available curricular materials and were given preference based on what teachers had completed in these classrooms in prior years to build multiplication fact fluency. All activities were determined to align with a skills and rehearsal approach prior to their implementation.

To compare the different approaches to developing multiplication fluency, we compared performance on a one-minute timed multiplication fact test of 30 facts (Appendix A) before the five weeks of instruction and immediately following the five week period. The facts chosen for the test were factors between 2 and 12. No facts with 0 or 1 was used and we ensured there would be squares (e.g. $6 \times 6,7 \times 7$ ) and more difficult facts that "anchor" facts could be used to solve. For example, $6 \times 8$ was chosen for the test as $5 \times 8$ could be used as an easier anchor fact.

\section{RESULTS}

We analyzed the student multiplication fluency data in a 2 (Group: Strategy versus Drill) x 3 (Grade: 3, 4, 5) x 2 (Time: Pretest versus Posttest) analysis of variance (ANOVA). The ANOVA revealed a main effect for Group, $\mathrm{F}(1,276)=34.10$, $\mathrm{MSe}=34.22, \mathrm{p}<.001$, eta-squared $=.11$; a main effect for Grade, $\mathrm{F}(2,276)=46.60$, $\mathrm{MSe}=34.22$, $\mathrm{p}<.001$, eta-squared $=.25$; and a main effect for Time, $\mathrm{F}(1,276)=215.19$, $\mathrm{MSe}=5.98, \mathrm{p}<.001$, eta-squared $=.44$. However, these main effects had to be interpreted conditionally because there was a three-way interaction was also significant, $\mathrm{F}(2,276)=10.54, \mathrm{MSe}=5.98, \mathrm{p}<.001$, eta-squared $=.07$. We conducted tests of simple effects to understand the nature of the three-way interaction. In particular, for each grade, we conducted a 2 (Group: Strategy versus Drill) x 2 (Time: Pretest versus Posttest) ANOVA.

For third grade, the two-way ANOVA revealed a main effect for Group, $F(1,48)=8.10$, MSe $=$ $19.90, \mathrm{p}=.006$, eta-squared $=.14$; and a main effect for Time, $\mathrm{F}(1,48)=20.15$, MSe $=6.34, \mathrm{p}<$ .001 , eta-squared $=.30$. However, the interaction was also significant, $F(1,48)=71.61$, MSe = $6.34, \mathrm{p}<.001$, eta-squared $=.60$. We conducted additional tests of simple effects to understand this two-way interaction. As seen in Table 1, pretest scores were significantly greater for the Drill group than for the Strategy group, $F(1,48)=5.26, p=.03$. In contrast, posttest scores were significantly greater for the Strategy group than for the Drill group, $F(1,48)=30.09$, $p<$ .001 . 
Figure 1. Grade 3 performance on a multiplication fluency pretest and posttest by group. Error bars represent the standard error of the mean.

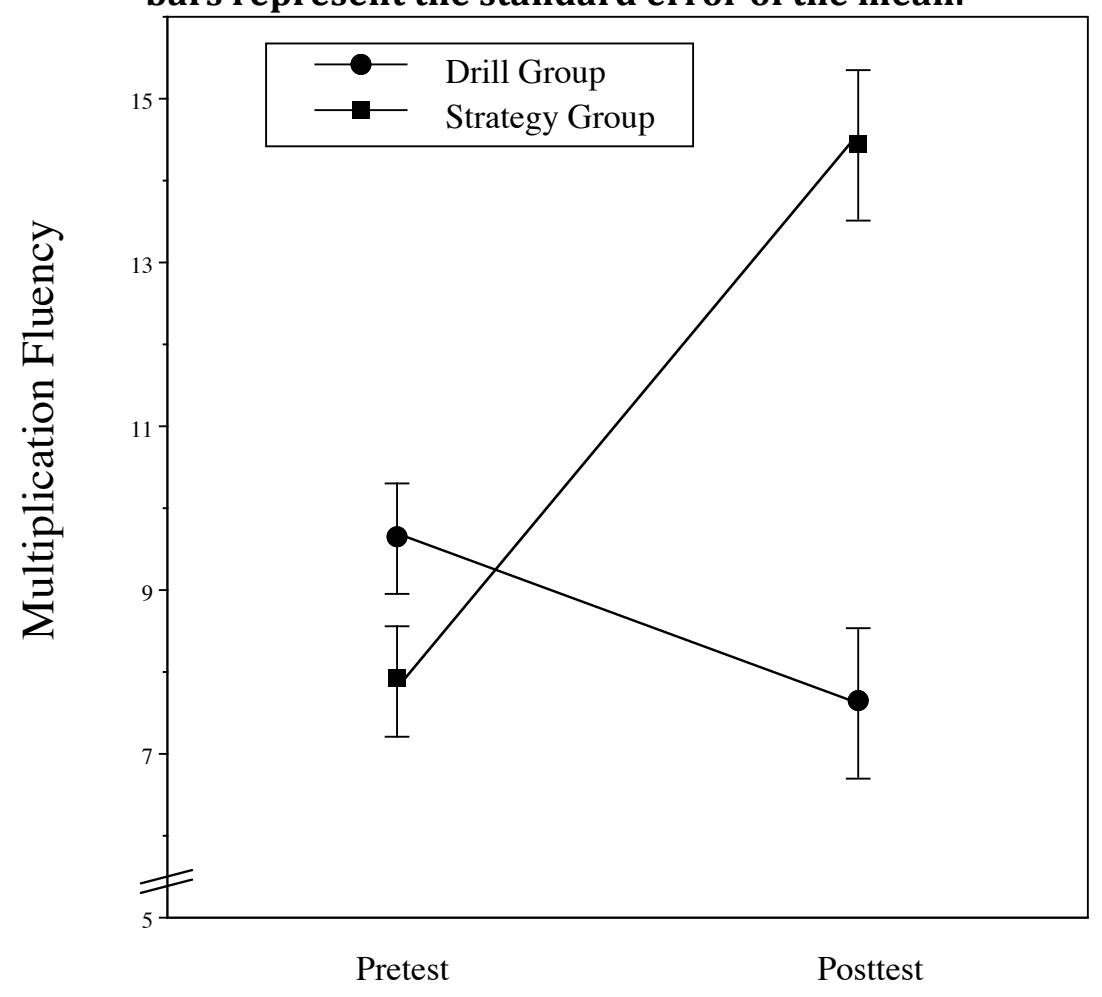

For fourth grade, the two-way ANOVA revealed a main effect for Group, $F(1,132)=17.22$, MSe $=26.44, \mathrm{p}<.001$, eta-squared $=.12$; and a main effect for Time, $\mathrm{F}(1,132)=285.26$, $\mathrm{MSe}=4.84$, $\mathrm{p}<.001$, eta-squared $=.66$. However, the interaction was also significant, $F(1,132)=74.58$, $\mathrm{MSe}=4.84, \mathrm{p}<.001$, eta-squared $=.36$. We conducted additional tests of simple effects to understand this two-way interaction. As seen in Table 1, pretest scores did not differ, $F(1,132)$ $<1$. In contrast, posttest scores were significantly greater for the Strategy group than for the Drill group, $\mathrm{F}(1,132)=40.41, \mathrm{p}<.001$.

Figure 2. Grade 4 performance on a multiplication fluency pretest and posttest by group. Error bars represent the standard error of the mean.

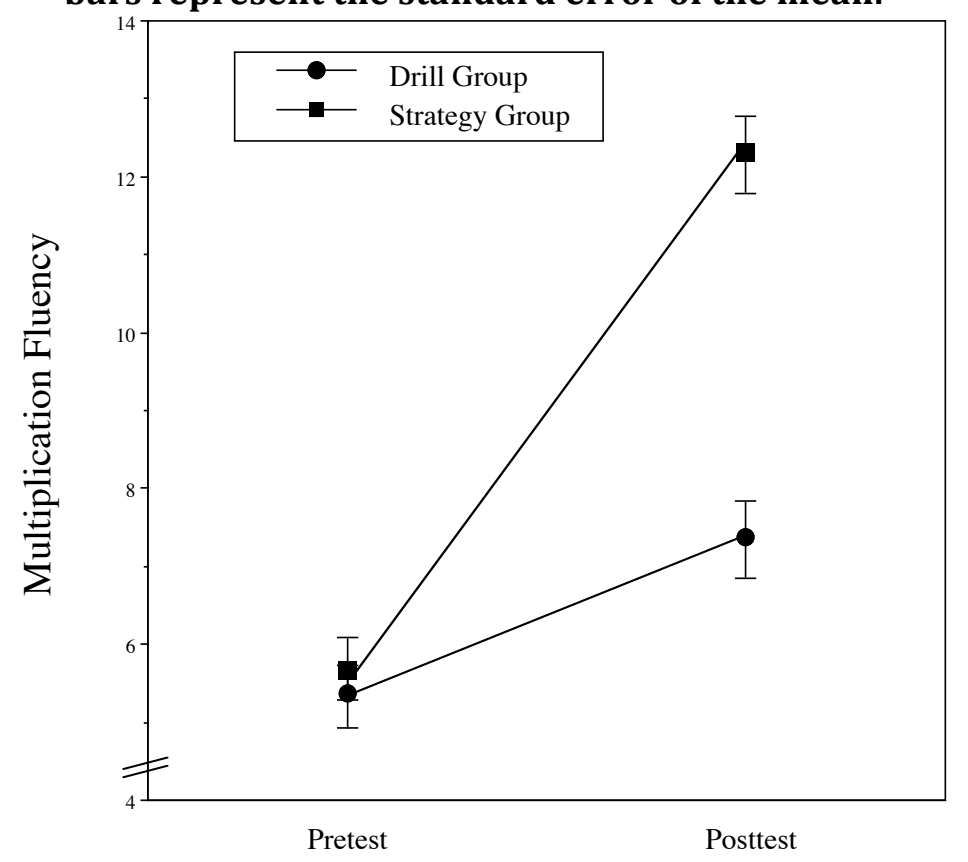


For fifth grade, the two-way ANOVA revealed a main effect for Group, $\mathrm{F}(1,96)=15.14$, MSe $=$ 52.07, $\mathrm{p}<.001$, eta-squared $=.14$; and a main effect for Time, $\mathrm{F}(1,96)=68.21$, MSe $=7.37, \mathrm{p}<$ .001 , eta-squared $=.41$. However, the interaction was also significant, $\mathrm{F}(1,96)=9.09$, MSe $=$ $7.37, \mathrm{p}=.003$, eta-squared $=.09$. We conducted additional tests of simple effects to understand this two-way interaction. As seen in Table 1, pretest scores significantly greater for the Strategy group than for the Drill group, $F(1,96)=7.34, p=.008$. Posttest scores were also significantly greater for the Strategy group than for the Drill group, $F(1,96)=20.26, p<.001$.

Figure 3. Grade 5 performance on a multiplication fluency pretest and posttest by group. Error

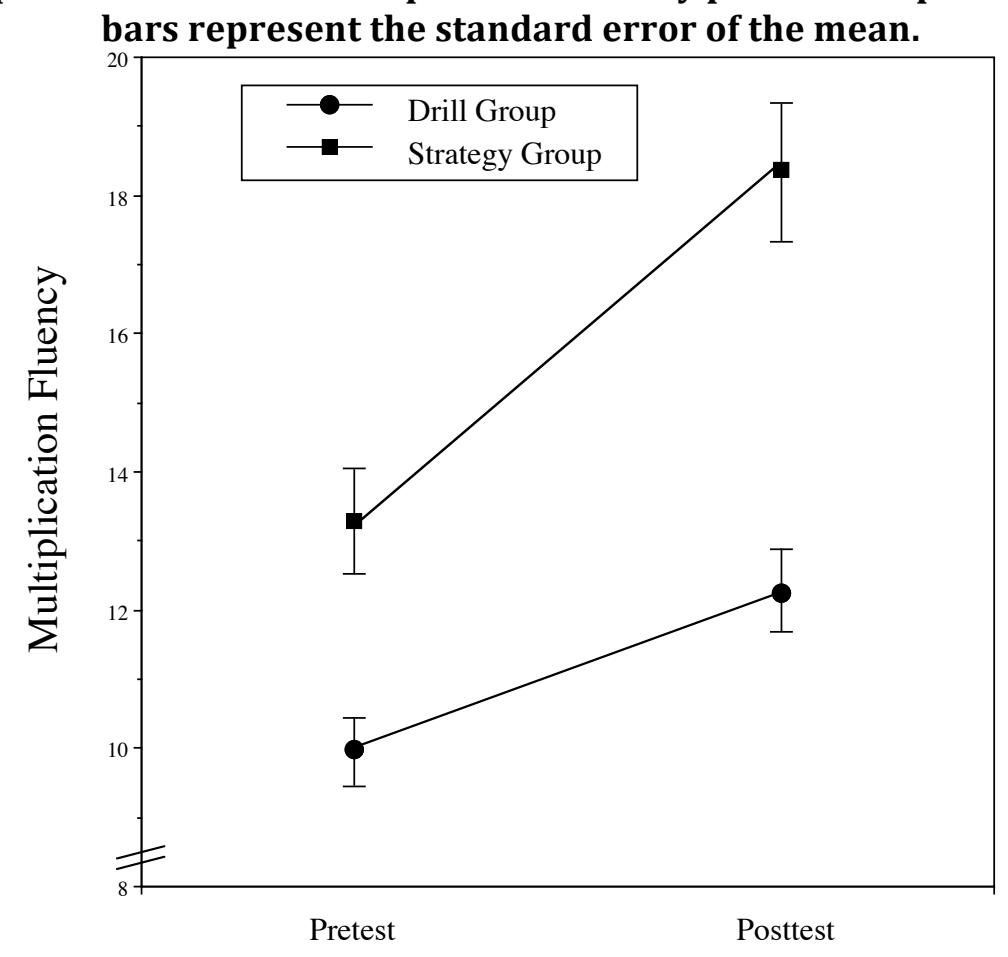

DISCUSSION

This study demonstrates that by providing students in grades 3,4 and 5 with 10 to 15 minutes of fact fluency practice each day through a social-interactional framework for five weeks, their fact fluency improves. Students receiving instruction through drill and rehearsal gained on average 0.79 facts per minute over the five weeks, with positive gains of 2 facts per minute in fourth grade 2.36 facts per minute in fifth grade. Students receiving instruction grounded in the social-interactional approach demonstrated an average gain of 6.08 facts per minute, with the highest gains in fourth grade of 6.65 facts per minute. This finding is consistent with other studies in that by providing students opportunities to learn their multiplication facts, they will improve over time through both approaches (Chung, 2004; Woodward, 2006). However, our study demonstrates that when students focus solely on drill-based practice for five weeks, they only gain slightly, while in the strategy group students gained 7.7 times as many more facts.

The evidence from this study also demonstrates that students receiving instruction grounded in a framework built upon Bruner's Modes of Representation combined with socialinteractional elements significantly outperform students who receive instruction grounded in a behavioristic theory of learning. These instructional activities designed for the Strategy group emphasized strategic thinking and mathematical relationships between multiplication facts and created greater and more consistent gains in fact fluency than activities emphasizing memorization and repetition. Although Brownell (1935) had similar conjectures and findings, 
more recently Russell (2000) found that students build an understanding of multiplication facts through problem solving and, then, sharing and examining their own strategies.

One of the implications to this finding involves memory: one might presume that students will remember any piece of information (including multiplication facts) more accurately if the information is connected to already easily-remembered information (Hiebert \& Carpenter, 1992). In the case of multiplication facts, this would mean that students who know $8 \times 5$ would ideally spend instructional time learning to use that knowledge to solve $8 \times 4,8 \times 6$, and $8 \times 7$ and so forth. Time spent building flexibility with facts would in turn produce fluency with facts as students would have related strategies to refer to should memory fail them. This would contrast with a similar amount of time being spent by students trying to commit $8 \times 4,8 \times 6,8 \times 7$, etc. to memory.

Our study shows evidence that students in the Strategy group made much larger gains than students in the Drill group. The sample was too small to examine the differences among students of special populations. However, several continuations of this study would serve promising to the field of fact fluency research. Specifically, analyzing the impact of cognitive and social-interactional approaches for populations such as English Language Learners or Special Education students. This would help us articulate whether these theories apply broadly to students from a variety of backgrounds. Woodward (2006) found that an integrated approach focusing on basic facts, extended facts, partial products and methods for approximation, helped students with learning disabilities learn basic facts as well as more extended facts than the control group.

One difference in our approach than other approaches, which may allow for an increase in fact fluency across different students, is that we utilize Bruner's (1964) modes of representations and progressive formalization (Freudenthal, 1973, 1991; Gravemeijer, 1999; Treffers, 1987) through social interaction (Carpenter \& Lehrer, 1999), as an instructional framework for progressively formalizing student thinking. Instead of having students use only manipulatives or technology to develop their fact understanding, which has had marginal success for most populations of students (Fuson, 2003; Russell, 2000; Wong \& Evans, 2007), we encourage students to explain their enactive model and then progressively formalize that understanding by pressing them to create an iconic model such as a number line or array. Once students formalize these models, we encourage them to connect these prior ideas to different symbolic representations, typically the ratio table and partial products. When students use their prior knowledge combined with arrays and symbolic representations Young-Loveridge and Mills (2009) demonstrated greater gains in student achievement.

A final implication for this study is the foundation for building understanding with multi-digit multiplication. Once students have a solid understanding of and flexibility with single digit multiplication, which implies the ability to use different models to represent different situations and the ability to articulate why they work, we hypothesize that they are ready to begin building a deeper understanding of multiplication that allows them to solve different types of contextual problems, move more fluidly into proportional thinking, and to understand algebraic structures such as equality, relationships, and the commutative, associative, and distributive properties (Baek, 2006; Young-Loveridge \& Mills, 2009).

Ultimately fact fluency, regardless of the operation, is a trait that supports student learning of mathematics in various forms throughout their school career (NMAP, 2008). However, acknowledging the importance of fact fluency and determining the most effective method to increase students' fact fluency are two different propositions. A behavioristic approach with an 
emphasis on memorization and repetition was demonstrated in this study to be less effective than an approach built from theories emphasizing relational thinking and building of mental schemas for facts that students find easier to remember. In essence, building flexibility through a socio-cognitive framework using a variety of facts enhances fluency with basic facts.

\section{ACKNOWLEDGEMENTS}

The work reported in this paper was funded by the Mathematics, Science Partnership (MSP) grant as administered by the Idaho Department of Education (IDE) along with a grant from the Micron Foundation. The work was supported by the Center for School Improvement and Policy Studies (CSIPS) at Boise State University. The content of the paper, however, does not necessarily represent the position or policies of IDE, BSU, or CSIPS. 


\section{References}

Baek, J. M. (2006). Children's mathematical understanding and invented strategies for multidigit multiplication. Teaching Children Mathematics, 12(5), 242.

Barmby, P., Harries, T., Higgins, S., \& Suggate, J. (2009). The array representation and primary children's understanding and reasoning in multiplication. Educational Studies in Mathematics, 70, 217-241.

Baroody, A. J., \& Dowker, A. (Eds.). (2003). The development of arithmetic concepts and skills: Constructing adaptive expertise. Mahwah, NJ: Lawrence Earlbaum Associates.

Beishuizen, M., \& Anghileri, J. (1998). Which mental strategies in the early number curriculum? A comparision of British ideas and Dutch views. British Educational Research Journal, 24(5), 519-538.

Boonlerts, S., \& Inprasitha, M. (2013). The Textbook Analysis on Multiplication: The Case of Japan, Singapore and Thailand. Creative Education, 4(4).

Brownell, W. A. (1935). Psychological considerations in the learning and teaching of arithmetic. In W. D. Reeve (Ed.), The teaching of arithmetic, Tenth yearbook of the National Council of Teachers of Mathematics (pp. 1-31). New York, NY: Teachers College Press.

Bruner, J. S. (1964). The course of cognitive growth. American Psychologist, 19(1), 1-15.

Bruner, J. S. (1966). Toward a theory of instruction. Cambridge, Mass: Belkapp Press.

Campbell, J. I., Chen, Y., \& Maslany, A. J. (2013). Retrieval-induced forgetting of arithmetic facts across cultures. Journal of Cognitive Psychology, 25(6), 759-773.

Carpenter, T. P., \& Lehrer, R. (1999). Teaching and learning mathematics with understanding. In E. Fennema \& T. Romberg (Eds.), Mathematics Classrooms that Promote Teaching for Understanding (pp. 19 - 32). Mahwah, NJ: Lawerance Erlbaum Associates.

Chung, I. (2004). A Comparative Assessment of Constructivist and Traditionalist Approaches to Establishing Mathematical Connections in Learning Multiplication. Education, 125(2), 271.

Cobb, P., Yackel, E., \& Wood, T. (1993). Discourse, mathematical thinking, and classroom practice. In E. A. Forman, N. Minick \& C. A. Stone (Eds.), Contexts for learning: Sociocultural dynamics in children's development (pp. 91119). New York: Oxford University Press.

Codding, R. S., Burns, M. K., \& Lukito, G. (2011). Meta-Analysis of Mathematic Basic-Fact Fluency Interventions: A Component Analysis. Learning Disabilities Research \& Practice, 26(1), 36-47.

Duncan, G. J., Dowsett, C. J., Claessens, A., Magnuson, K., Huston, A. C., Klebanov, P., ... Duckworth, K. (2007). School readiness and later achievement. Developmental Psychology, 43, 1428-1446.

Freudenthal, H. (1973). Mathematics as an educational task: Springer.

Freudenthal, H. (1991). Revisiting Mathematics Education: China Lectures.

Fuson, K. C. (2003). Toward computational fluency in multidigit multiplication and division. Teaching Children Mathematics, 9(6), 300-305.

Geary, D. C. (2004). Mathematics and learning disabilities. Journal of Learning Disabilities, 37, 4-15.

Geary, D. C., Bow-Thomas, C., Liu, F., \& Siegler, R. S. (1996). Development of arithmetical competencies in Chinese and American children: Influence of age, language, and schooling. Child Development, 67(5), 2022-2044.

Geary, D. C., Hoard, M. K., Byrd-Craven, J., Nugent, L., \& Numtee, C. (2007). Cognitive mechanisms underlying achievement deficits in children with mathematical learning disability. Child Development, 78(4), 1343-1359.

Gravemeijer, K. (1999). How emergent models may foster the constitution of formal mathematics. Mathematical Thinking and Learning, 1(2), 155-177.

Gray, E., Pitta, D., \& Tall, D. (2000). Objects, actions, and images: A perspective on early number development. The Journal of Mathematical Behavior, 18(4), 401-413.

Henry, V. J., \& Brown, R. S. (2008). First-grade basic facts: An investigation into teaching and learning of an accelerated, high-demand memorization standard. Journal for Research in Mathematics Education, 39(2), 153183.

Hiebert, J., \& Carpenter, T. P. (1992). Learning and teaching with understanding. In D. A. Grouws (Ed.), Handbook of Research on Mathematics Teaching and Learning (pp. 65-97). New York: Macmillan. 
Jordan, N. C., Hanich, L. B., \& Kaplan, D. (2003). A longitudinal study of mathematical competencies in children with specific mathematics difficulties versus children with comorbid mathematics and reading difficulties. Child Development, 74(3), 834-850.

Kilpatrick, J., Swafford, J., \& Findell, B. (2001). Adding it up: helping children learn mathematics

Mulligan, J., \& Mitchelmore, M. (2009). Awareness of pattern and structure in early mathematical development. Mathematics Education Research Journal, 21(2), 33-49.

National Mathematics Advisory Panel. (2008). Foundations for success: The final report of the National mathematics advisory panel. Washington, D.C.: US Department of Education.

Nelson, P. M., Burns, M. K., Kanive, R., \& Ysseldyke, J. E. (2013). Comparison of a math fact rehearsal and a mnemonic strategy approach for improving math fact fluency. Journal of school psychology, 51(6), 659-667.

NMAP. (2008). Foundations for success: The final report of the National Mathematics Advisory Panel. Washington D.C.: U.S. Department of Education, Office of Planning, Evaluation and Policy Development.

Reese, C. M., Miller, K. E., Mazzeo, J., \& Dossey, J. A. (1997). NAEP 1996 Mathematics Report Card for the Nation and the States. Washington, DC: National Center for Education Statistics.

Russell, S. J. (2000). Developing computational fluency with whole numbers in the elementary grades. The New England Math Journal, 32(2), 40-54.

Speiser, R., Schneps, M. H., Heffner-Wong, A., Miller, J. L., \& Sonnert, G. (2012). Why is paper-and-pencil multiplication difficult for many people? The Journal of Mathematical Behavior, 31(4), 463-475.

Star, J. R., \& Madnani, J. K. (2004). Which way is the "best"? Students' conceptions of optimal strategies for solving equations. Paper presented at the Annual meeting of the North American Chapter of the International Group for the Psychology of Mathematics Education, Toronto, Canada.

Steffe, L. P. (1979). A reply to "Formal thinking Strategies: A prerequisite for learning basic facts"? Journal for Research in Mathematics Education, 10(5), 370-374.

Thornton, C. A. (1978). Emphasizing thinking strategies in basic fact instruction. Journal for Research in Mathematics Education, 9(3), 214-227.

Treffers, A. (1987). Three dimensions: A model of goal and theory description in mathematics instruction - The Wiskobas Project. . Reidel: Dordrecht, The Netherlands.

Van Amerom, B. A. (2003). Focusing on informal strategies when linking arithmetic to early algebra. Educational Studies in Mathematics, 54(1), 63-75.

Van Putten, C. M., van den Brom-Sniiders, P. A., \& Beishuizen, M. (2005). Progressive mathematization of long division strategies in Dutch primary schools. Journal for Research in Mathematics Education, 36(1), 44-73.

Wong, M., \& Evans, D. (2007). Improving basic multiplication fact recall for primary school students. Mathematics Education Research Journal, 19(1), 89-106.

Woodward, J. (2006). Developing automaticity in multiplication facts: Integrating strategy instruction with timed practice drills. Learning Disability Quarterly, 29(4), 269-289.

Young-Loveridge, J., \& Mills, J. (2009). Teaching multi-digit multiplication using array-based materials. Crossing divides, 635-642. 
Table 1. Pre and posttest results: Correct facts in one-minute.

\begin{tabular}{ccccc}
\hline Group & $\mathbf{N}$ & $\begin{array}{c}\text { Pre } \\
\text { Mean (SD) }\end{array}$ & $\begin{array}{c}\text { Post } \\
\text { Mean (SD) }\end{array}$ & $\begin{array}{c}\text { Gain } \\
\text { Mean (SD) }\end{array}$ \\
\hline $\mathbf{3}^{\text {rd }}$ grade Drill & 25 & $9.64(2.55)$ & $7.64(3.11)$ & $-2.00(2.94)$ \\
$\mathbf{3}^{\text {rd }}$ grade Strategy & 25 & $7.92(2.75)$ & $14.44(5.36)$ & $6.52(4.00)$ \\
\hline $\mathbf{4}^{\text {th }}$ grade Drill & 69 & $5.38(3.69)$ & $7.38(3.97)$ & $2.00(2.20)$ \\
$\mathbf{4}^{\text {th }}$ grade Strategy & 65 & $5.66(2.91)$ & $12.31(4.98)$ & $6.65(3.05)$ \\
\hline $\mathbf{5}^{\text {th }}$ grade Drill & 74 & $9.99(4.64)$ & $12.35(5.41)$ & $2.36(3.62)$ \\
$\mathbf{5}^{\text {th }}$ grade Strategy & 24 & $13.29(5.65)$ & $18.38(6.49)$ & $5.08(4.01)$ \\
\hline Average & & $8.34(3.63)$ & $9.12(4.16)$ & $0.79(2.92)$ \\
& & $8.96(3.77)$ & $15.04(5.61)$ & $6.08(3.69)$ \\
\hline
\end{tabular}

APPENDIX A

Name: Date: School:

Teacher: Grade:

Multiplication Fluency Pre-----Post (circle one)

(fold this section back and complete with the Test portion face down)a 
Brendefur, J., Strother, S., Thiede, K., \& Appleton, S. (2015). Developing Multiplication Fact Fluency. Advances in Social Sciences Research Journal, 2(8) 142-154.

\begin{tabular}{|c|c|c|c|c|}
\hline $7 \times 5=$ & $6 \times 10=$ & $4 \times 4=$ & $5 \times 8=$ & $10 \times 7=$ \\
\hline $6 \times 6=$ & $7 \times 6=$ & $6 \times 11=$ & $4 \times 5=$ & $6 \times 8=$ \\
\hline $9 \times 7=$ & $8 \times 6=$ & $4 \times 8=$ & $12 \times 7=$ & $9 \times 5=$ \\
\hline $2 \times 12=$ & $5 \times 4=$ & $10 \times 8=$ & $8 \times 5=$ & $10 \times 6=$ \\
\hline $9 \times 4=$ & $12 \times 6=$ & $7 \times 7=$ & $5 \times 11=$ & $3 \times 7=$ \\
\hline $6 \times 3=$ & $7 \times 8=$ & $12 \times 8=$ & $3 \times 6=$ & $4 \times 9=$ \\
\hline
\end{tabular}

